\title{
UMA EXPERIÊNCIA DE PRODUÇÃO DE VIDEOAULA EXPERIMENTAL EM AULAS DE QUÍMICA
}

\section{AN EXPERIENCE OF EXPERIMENTAL VIDEOAULA PRODUCTION IN CHEMITRY CLASSROOMS}

\author{
Raissa Cristina Pires ${ }^{1}$ \\ Cristiane Beatriz Dal Bosco Rezzadori ${ }^{2}$
}

\begin{abstract}
Resumo: A utilização dos telefones celulares em sala de aula com fins pedagógicos é crescente. Neste sentido, a produção de vídeos ganha espaço como ferramenta de ensino ao possibilitar aprendizagem significativa a partir do envolvimento e interesse dos alunos. Assim, este relato visa apresentar uma experiência com a utilização de videoaulas experimentais produzidas por alunos do $3^{\circ}$ ano do Ensino Médio de uma escola pública da cidade de Londrina-PR. A produção da videoaula experimental foi baseada em um roteiro elaborado pelos alunos e a coleta de dados foi feita por meio dos vídeos produzidos e de questionário aplicado antes e depois da atividade. A partir da análise dos questionários e vídeos produzidos, podemos inferir que a produção de uma videoaula experimental tem grande efetividade ao facilitar o processo de ensino-aprendizagem, possibilitar as diferentes formas de expressão do aluno, bem como promover a autonomia e protagonismo estudantil.
\end{abstract}

Palavras-chave: Ensino de Química; Produção de Vídeo; Videoaula experimental; Tecnologia da Informação e Comunicação (TIC).

\begin{abstract}
The use of cell phones in the classroom for educational purposes is increasing. Video lessons production gains space as a teaching tool by enabling meaningful learning from the involvement and interest of the students. Thus, it aims to present an experience with experimental video lessons produced by students of the 3rd year of high school in a public school in Londrina-PR. To this end, a theoretical class of concepts was developed and, in sequence, the production of the. The experimental video lessons production was based on a script prepared by the students and the data collection was done through videos produced and some questions were applied before and after the activity. From the analysis of the questionnaires and videos produced, we can infer that the production of experimental video lessons had great effectiveness in facilitating the teaching-learning process, enabling different forms of student expression, as well as promoting student autonomy and protagonism.
\end{abstract}

Keywords: Chemistry teaching; Video production; Experimental video lessons; Information and communication technology.

\section{Introdução ao estudo}

A atualização da Lei de Diretrizes e Bases da Educação na década de 90 (LDB/96) resultou em uma reforma do ensino brasileiro. A partir deste momento a educação básica

\footnotetext{
${ }^{1}$ Licenciada em Química pela Universidade Tecnológica Federal do Paraná (UTFPR) - Campus

Londrina, Londrina, Paraná, Brasil. E-mail: rcp22@live.com

${ }^{2}$ Doutora em Ensino de Ciências e Educação Matemática pela Universidade Estadual de Londrina (UEL).

Docente do Curso de Licenciatura em Química pela Universidade Tecnológica Federal do Paraná

(UTFPR) - Campus Londrina, e do Programa de Mestrado Profissional em Química em Rede Nacional

(UEL), Londrina, Paraná, Brasil. E-mail: crezzadori@utfpr.edu.br
} 
passou a ser pautada no pensamento de "aprender para a vida" (KUENZER, 2000), voltado à formação cidadã do aluno.

Em 1997, os Parâmetros Curriculares Nacionais (PCN), contribuíram para a implementação de novas metodologias e ferramentas para melhorar a qualidade do ensino ofertado, dentre elas as tecnologias da informação e comunicação (TIC). O PCN+ Ensino Médio - Ciências da Natureza, Matemática e suas Tecnologias (BRASIL, 2006, p. 139) destaca a necessidade atual da adoção desta perspectiva

\begin{abstract}
Não é possível também, em pleno século 21, abrir mão dos recursos oferecidos pela tecnologia da informação e da comunicação e da capacitação dos professores para a utilização plena desses recursos. Nas últimas décadas, o custo financeiro desses equipamentos tem decrescido na mesma proporção da sua crescente relevância para a formação de alunos e professores, de forma que é inadiável nosso esforço em mudar atitudes refratárias a seu uso, uma vez que estão amplamente disseminados na vida social em geral.
\end{abstract}

Ainda, sobre a utilização das TIC nas escolas, podemos afirmar que há grande potencial de aplicação, dependendo da utilização das ferramentas e informações contidas nestas, por professores e alunos, como afirma o Comitê Gestor da Internet no Brasil (CGI) (2017, p. 27):

\begin{abstract}
O uso das tecnologias de comunicação e informação (TIC) é um dos fatores que define a oferta de educação de qualidade. A disponibilidade dessas ferramentas nas escolas, associada ao seu uso crítico por professores e alunos, pode potencializar os benefícios educativos das TIC, como facilitar o acesso dos indivíduos ao conhecimento e expandir as oportunidades de participação e engajamento social, cultural e econômico.
\end{abstract}

Entre as diversas Tecnologias de Informação e Comunicação (TIC) que podem ser utilizadas com fins pedagógicos, podemos ressaltar os telefones celulares como uma ferramenta produtiva para ser usada em sala de aula devido a sua acessibilidade, quase universal, como é ilustrado no Gráfico 1. 
DOI: http://dx.doi.org/10.33238/ReBECEM.2019.v.3.n.1.22069

Gráfico 1: Percentual de indivíduos que possuem telefone celular por região em 2017

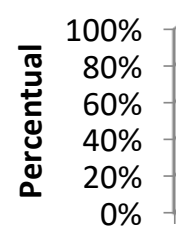

Não Sabe<smiles>CC(C)C</smiles>

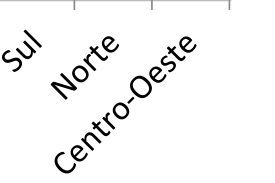
Não - Sim

Região

Fonte: Adaptado de $\mathrm{CGI}^{3}$ (2017)

Além disso, podemos analisar a posse de celulares por faixa etária, ilustrada no Gráfico 2. Se considerarmos que o público-alvo que fará parte deste relato de experiência possui idade entre 16 a 24 anos, podemos constatar que a sua grande maioria possui o aparelho celular.

Gráfico 2: Percentual de indivíduos que possuem telefone celular por idade em 2017

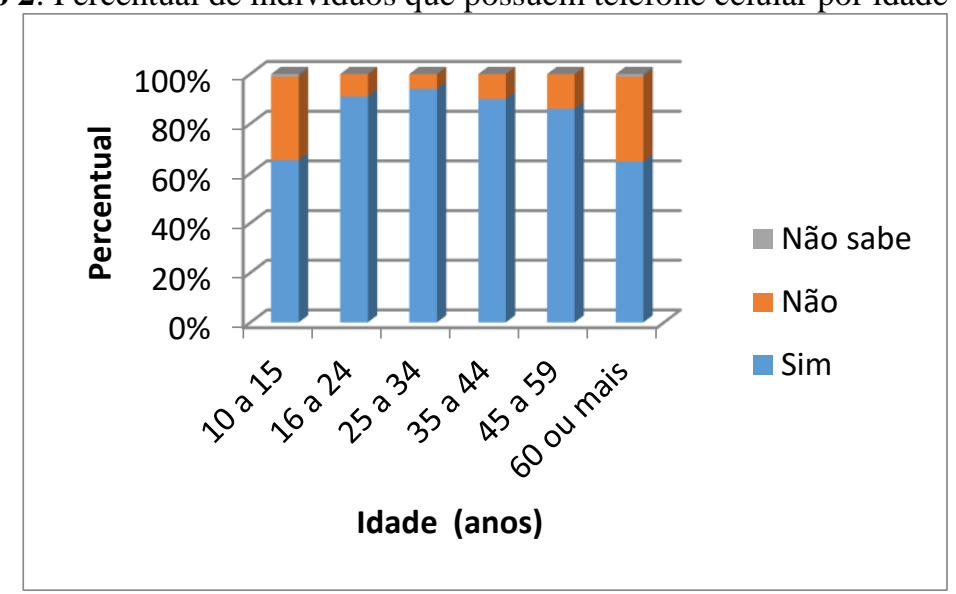

Fonte: Adaptado de CGI (2017)

Este grande acesso ao aparelho de telefone celular potencializa sua adoção como ferramenta pedagógica nas salas de aula, sendo seu uso crescente com o passar nos anos, como o Comitê Gestor da Internet no Brasil (2017, p. 29) afirma:

O uso do telefone celular está presente também nas atividades de ensino e
aprendizagem. Em $2015,36 \%$ dos professores de escolas públicas afirmavam
realizar atividades educacionais com o uso do telefone celular, esse percentual
subiu para $53 \%$ em 2017 . Entre os professores de escolas particulares, o
percentual era de $46 \%$ em 2015 , passando para $69 \%$ em 2017 . A proporção de
alunos que afirmaram utilizar o dispositivo para realizar atividades para a

\footnotetext{
${ }^{3}$ https://www.cgi.br/media/docs/publicacoes/2/tic_dom_2017_livro_eletronico.pdf (Adaptado)
} 
escola a pedido dos professores confirma a sua relevância no processo de aprendizagem: $53 \%$ entre os alunos de escolas públicas e $60 \%$ entre os de escolas particulares.

Todas as funções que os celulares apresentam, como câmera, gravador de voz, aplicativos e outros, podem ser utilizadas com propósitos educacionais (RIBAS; SILVA; GALVÃO, 2015), sendo papel do professor mediar à interação aluno-TIC. Logo, fazer uso da TIC pela TIC não influencia no desempenho do aluno que depende do professor criar uma situação criativa e desafiadora com a mesma para que o aluno possa atingir um determinado objetivo educacional.

Muitos estudos apontam que a utilização do celular como ferramenta pedagógica está intrinsecamente relacionada com a internet. Porém, a maior parte dos colégios estaduais do Núcleo Regional de Educação de Londrina não possui infraestrutura que garanta acesso à internet. Então, os docentes devem encontrar formas de utilizar as tecnologias de maneira alternativa, sem a necessidade de dependência da internet.

Neste sentido, a alternativa adotada e que será apresentada neste relato foi à produção de vídeos em sala de aula que exigiu somente a câmera dos telefones celulares dos alunos.

Sabany (2013, p. 19) declara que a produção de vídeos contribui para o “[...] desenvolvimento do pensamento crítico, promoção da expressão e da comunicação, favorecimento de uma visão interdisciplinar, integração de diferentes capacidades e inteligências, valorização do trabalho em grupo". Ainda, Vargas, Rocha e Freire (2007) defendem a ideia de que a produção de vídeos pode provocar motivação nos alunos, podendo incluir e estimular até mesmo aquele aluno que não se engaja nas aulas regulares. Assim, pode-se concluir que a produção de vídeos digitais tem grande potencial educacional (VARGAS; ROCHA; FREIRE, 2007).

Moran (1995) elenca e descreve sete classificações da utilização de vídeos em sala de aula, sendo estas: sensibilização, ilustração, simulação, conteúdo de ensino, produção, avaliação e integração/suporte de outras mídias. A produção de vídeos, foco deste relato, é dividida em três categorias, e dentre elas, a proposta aqui trabalhada se encaixa como forma de expressão. Utilizar o vídeo como expressão possibilita a integração de várias linguagens a partir da criatividade dos alunos. É uma experiência envolvente que pode incentivar o aprendizado (MORÁN, 1995). 
A produção de vídeos, segundo Vargas, Rocha e Freire (2007) contem três etapas: pré-produção, produção e pós-produção. A fase de pré-produção adotada neste relato foi a elaboração de um roteiro que conta com a descrição detalhada do que acontecerá no vídeo, sendo esta a preparação para a fase de produção. Na fase de produção, o vídeo é gravado de acordo com o roteiro elaborado e pode ser feito em tomadas caso ocorra algum erro. E, por fim, a fase pós-produção seria a análise e adequação deste vídeo, a edição (VARGAS; ROCHA; FREIRE, 2007).

Portanto, este relato visa apresentar a nossa experiência com a utilização de videoaulas experimentais produzidas por alunos do $3^{\circ}$ ano do Ensino Médio de uma escola pública da cidade de Londrina-PR, no contexto das aulas de Estágio Supervisionado do curso de Licenciatura em Química, da UTFPR - Campus Londrina. Para tanto, os alunos foram instigados a utilizar sua criatividade e conhecimentos adquiridos em sala de aula sobre a temática Cinética Química, em especial, os fatores que alteram a velocidade das reações químicas, para produzir os vídeos que serão apresentados e discutidos neste relato.

\section{A dinâmica da experiência}

A atividade proposta neste relato foi desenvolvida com 24 alunos matriculados em uma turma de $3^{\circ}$ ano do Ensino Médio, de um colégio público, localizado na cidade de Londrina, Paraná. O Colégio atende alunos de todas as classes sociais, sendo a maioria proveniente de bairros pobres e favelas.

Durante o processo de observações das aulas dessa turma, percebemos que os alunos eram agitados e que consideravam a atividade de estudar, em particular, a Química, chata. Ainda, ficou evidente o interesse dos alunos na utilização dos seus celulares sem fins pedagógicos, sendo que o professor regente da disciplina descrevia o aparelho como a "extensão do braço dos alunos". Dada estas constatações, traçamos como objetivo desenvolver um trabalho diferenciado com esta classe para mudar esta visão da disciplina e, para isso, decidimos utilizar o dispositivo que tanto adoravam, aliando os seus interesses com os nossos propósitos.

A partir desta demanda, com a metodologia e o recurso definidos, nos vimos em uma situação desafiadora: "Como utilizar o celular sem internet?”, pois como a escola não possuía infraestrutura para conexão online, precisávamos de uma alternativa. Assim, 
nos inspiramos na criação de podcast relatada por Ribas, Silva e Galvão (2015) no ensino de física. Nesta experiência, os alunos gravaram áudios sobre determinados temas da disciplina de física, com vistas a produzir conhecimento a partir da pesquisa, capacidade de síntese dos assuntos e adequação da linguagem. Outra vantagem desta ferramenta é a capacidade de reprodução, sendo que o aluno pode repeti-lo diversas vezes para melhor entendimento.

Frente a esta proposta, pensamos que, ao invés de utilizar apenas o áudio como foi proposto por esses autores, seria mais produtivo a utilização do vídeo, pois a Química é uma matéria muito visual.

Então, com o objeto de aprendizagem escolhido, optamos por propor a produção de um vídeo, pois na nossa percepção a produção se mostrava mais efetiva do que apenas a reprodução de um vídeo. Na produção do vídeo os alunos são ativos durante o processo de construção do conhecimento, enquanto ao assistir o vídeo são meramente passivos.

Pensando neste vídeo, resolvemos alterá-lo para o formato videoaula, no qual o conteúdo abordado deve ser explicado para gerar uma aprendizagem mais significativa. Como a Química é uma Ciência experimental, resolvemos aliar a produção do vídeo a um experimento, já que as atividades experimentais são consideradas interessantes e contribuem para o processo de ensino-aprendizagem. Esta contribuição ocorre por meio da associação entre a experimentação e o caráter lúdico e motivador, que gera interesse através dos sentidos. Ao mesmo tempo, as aulas práticas são responsáveis pelo aumento da capacidade de aprendizagem do aluno porque ocorre a motivação e o envolvimento deste ao objeto de estudo (GIORDAN, 1999).

Para efetuar a atividade proposta tivemos que pedir permissão da direção do colégio, do professor e dos próprios alunos participantes. Além da permissão, solicitamos aos alunos consentimento de uso de voz e imagem para divulgação posterior destes vídeos. Esclarecemos do que se tratava a atividade e os estudantes nos pareceram muito entusiasmados.

A proposta foi realizada durante duas aulas conjugadas de 50 minutos cada, divididas em dois momentos. Antes de iniciar a aula, fornecemos um questionário para verificar a opinião prévia dos alunos a respeito dos vídeos. 
No primeiro momento da aula, a intenção foi projetar o vídeo "Velocidade das mudanças: Evolução das tecnologias de comunicação"4 (DALE CARNEGIE DF, 2009), cujo tema era a evolução dos meios de comunicação. Este vídeo foi utilizado para atrair a atenção e aguçar a curiosidade dos alunos.

Em seguida, iniciamos uma discussão sobre os diferentes meios de comunicação e suas vantagens e desvantagens. Deste modo, a discussão foi mediada até alcançar o conceito de rapidez e facilidade de comunicação, comparando os meios de comunicação antigos e novos, dando ênfase para o uso do celular, em especifico, o aplicativo "Whatsapp".

Então, debatemos a questão de aceleração de processos em geral, a necessidade que os seres humanos têm de aumentar a velocidade de tudo. Assim, abordamos a importância da velocidade nas indústrias e, então, nos processos químicos.

Pensando em processo químicos, reações químicas, lançamos uma situação: a preparação de um churrasco. Questionamos os alunos a respeito de quais itens eram necessários para essa preparação. Dentre os itens elencados pelos alunos estava o fogo, e assim, foi alcançada a questão: "Por que utilizar o fogo?".

A partir desta problemática, construímos o conceito de como a temperatura afeta a velocidade da reação. Para reforçar a ideia, discutida através da preparação de alimentos, utilizamos o simulador "Reações Reversíveis" (Figura 1), da PhET Colorado 5 . O simulador é considerado um Objeto de Aprendizagem (OA), pois trata-se de um material eletrônico que auxilia no processo de construção do conhecimento (CARNEIRO; SILVEIRA, 2014). Por meio deste OA, simulamos o aumento e diminuição da temperatura para observar a influência deste fator.

\footnotetext{
${ }^{4}$ https://www.youtube.com/watch?v=fcDzaPuZXj8

${ }^{5}$ https://phet.colorado.edu/pt_BR/simulation/reversible-reactions
} 


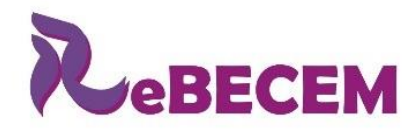

DOI: http://dx.doi.org/10.33238/ReBECEM.2019.v.3.n.1.22069
Revista Brasileira de Educação em

Ciências e Educação Matemática

ISSN 2594-9179

Figura 1: Interface do simulador "Reações Reversíveis".

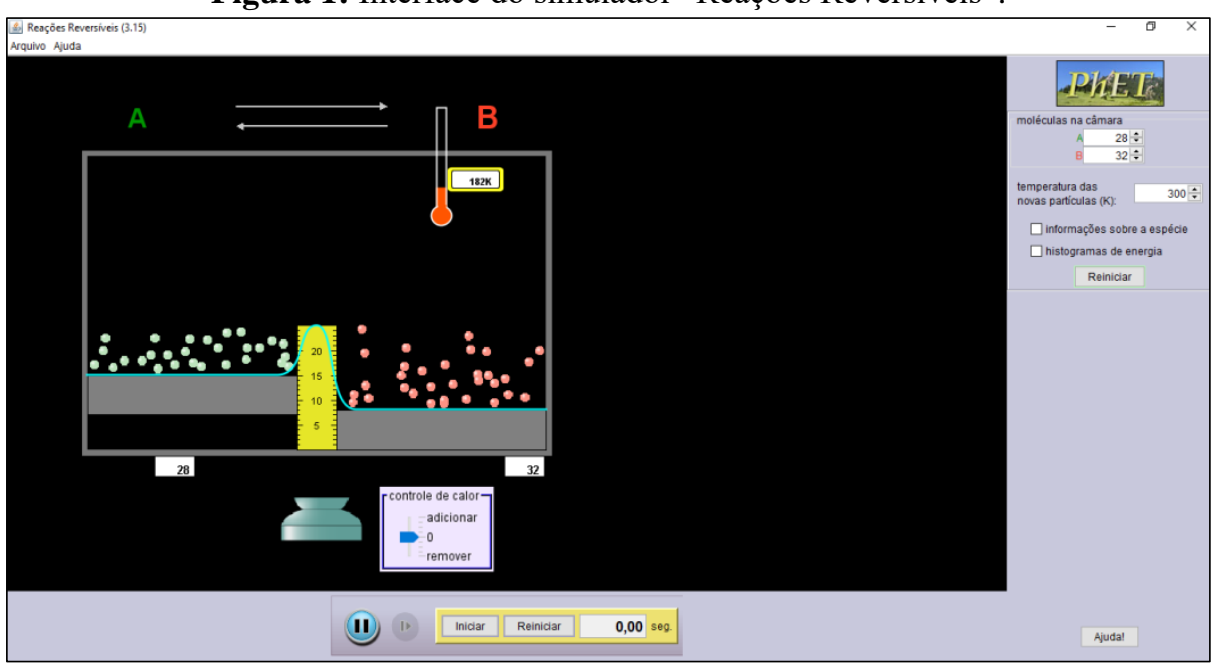

Fonte: PhET Colorado.

Em seguida, ainda na situação do churrasco, apresentamos a problemática: "De que forma a madeira ou o carvão é posto para queimar?". Neste momento, iniciamos a discussão sobre a influência da superfície de contato na velocidade das reações químicas. Para facilitar a assimilação do conceito "superfície de contato", uma imagem (Figura 2) representando duas pilhas de madeira foram projetadas com o intuito de questionar os alunos sobre em qual das situações o processo de queima seria mais rápido para fazê-los concluir que quanto maior a superfície exposta (Figura 3), maior a velocidade da reação.

Figura 2: Representação da superfície de contato

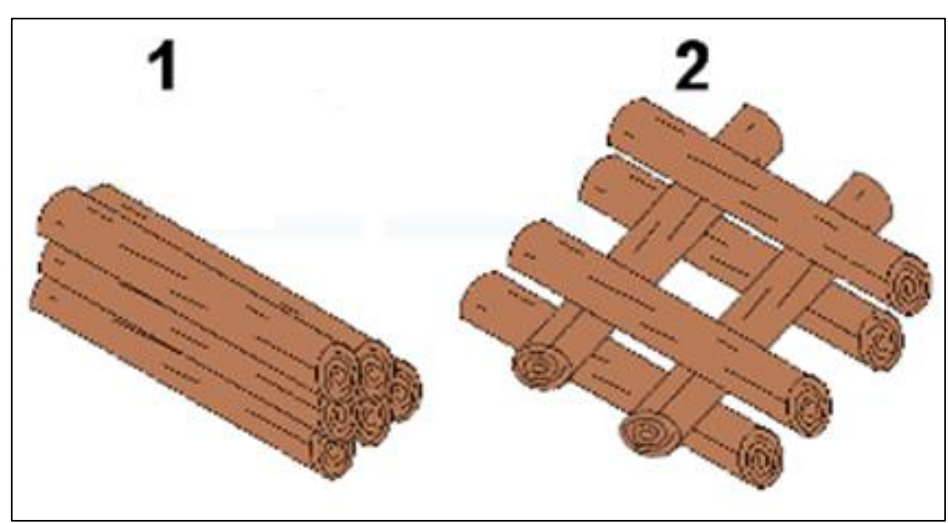

Fonte: Brasil Escola ${ }^{6}$

\footnotetext{
${ }^{6}$ https://brasilescola.uol.com.br/quimica/superficie-contato-velocidade-das-reacoes.htm
} 
Figura 3: Representação da superfície de contato

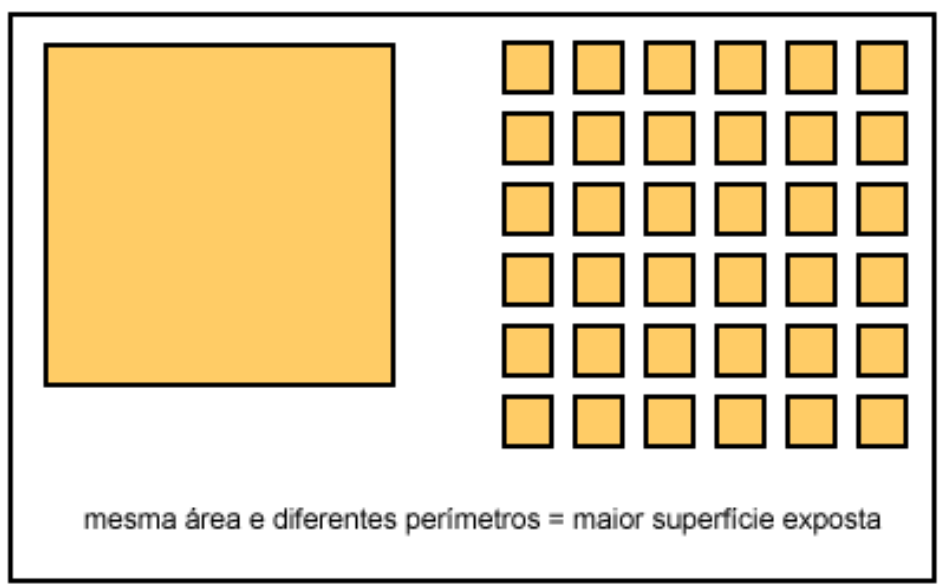

Fonte: Fazendo Química IFRJ ${ }^{7}$

Para finalizar o primeiro momento, apresentamos o seguinte questionamento: "Por que as pessoas abanam ou utilizam o secador de cabelos para acender o fogo?". Assim, discutimos a influência da concentração na velocidade das reações químicas. Utilizamos novamente o simulador "Reações Reversíveis" para facilitar o entendimento. Nesta etapa, criamos uma situação hipotética no simulador e cronometramos o tempo que cinco moléculas levariam para reagir. Em seguida, para comparar, aumentamos a concentração inicial de reagentes e novamente cronometramos o tempo que o mesmo número moléculas reagiria. Então, conseguimos observar a influência da concentração em relação ao tempo de reação.

No segundo momento da aula, propusemos a produção de uma videoaula experimental para que os alunos pudessem demonstrar o que conseguiram compreender do primeiro momento da aula. Para tanto, os desafiamos a produzirem uma videoaula com o auxílio de seus smartphones de no máximo 3 minutos de duração. Os alunos se organizaram em pequenos grupos de 4 a 5 pessoas e cada grupo sorteou um fator (temperatura, superfície de contato e concentração) para ser o tema de seu experimento.

Em seguida, cada grupo recebeu uma cópia do roteiro experimental de seu respectivo tema. Após ler o roteiro, os alunos deveriam responder as perguntas presentes no mesmo que norteariam a explicação do experimento. Para a etapa de pré-produção do vídeo, instruímos os estudantes a construírem um roteiro que deveria conter a dinâmica do vídeo, o resultado esperado da experiência e como este resultado seria explicado tendo

\footnotetext{
${ }^{7}$ http://fazendoquimicaifrj.blogspot.com/2015/11/fatores-que-afetam-velocidade-na.html
} 
como base os conhecimentos adquiridos na aula expositiva sobre o tema. Portanto, o vídeo não deveria conter o experimento por si só, além do experimento os alunos tinham a tarefa de entendê-lo e explicá-lo, utilizando sua criatividade e conhecimento.

Ao longo da produção dos vídeos, mediamos as discussões dos grupos, orientamos e esclarecemos dúvidas remanescentes da aula teórica. Os vídeos foram gravados durante a aula e os grupos tiveram a liberdade de fazer a produção do material em sala de aula, no corredor ou no pátio da escola.

Ao final da aula, os vídeos foram encaminhados para a professora via internet. Além disso, um questionário posterior à produção do vídeo foi aplicado com o objetivo de analisar a opinião dos estudantes sobre a proposta pedagógica realizada.

\section{Resultados da Experiência}

O planejamento da atividade foi um processo longo e difícil. O primeiro desafio foi encontrar uma TIC que não exigisse a utilização da internet. A resposta surgiu a partir das observações em sala, onde concluímos que o celular poderia ser utilizado com fins pedagógicos haja vista o interesse que os alunos demonstravam por este aparelho. Em seguida, ao traçar o vídeo como o objeto de aprendizagem a ser utilizado, refletimos sobre como propor isto aos alunos de maneira a atender as demandas educacionais. Notamos que teríamos que mediar todo o processo de produção dos vídeos, porém abrimos espaço para a interpretação dos alunos a respeito do assunto.

Para dar suporte à produção das videoaulas experimentais, pensamos em desenvolver uma aula teórica para fornecer mínimo embasamento teórico. Nesta aula teórica, nos deparamos com outros desafios, como ilustrar a influência dos fatores na velocidade da reação. Então, optamos por utilizar outros objetos de aprendizagem, como o simulador e as imagens, sendo que a associação destes facilitou a compreensão dos conceitos. Por fim, pensamos em como avaliaria esta aula e concluímos que o vídeo seria o objeto de avaliação. Então, consideramos o produto final e a participação durante a produção do mesmo, formando uma avaliação processual.

No dia que visitamos o colégio com intuito de pedir autorização para a direção e consentimento dos alunos para poder utilizar o celular em sala de aula com fins pedagógicos, nos surpreendemos pelo apoio e abertura que o colégio nos proporcionou, e, principalmente, com a reação dos alunos. Pedimos alguns minutos para o professor que 
estava na sala para explicar a proposta. Neste momento, percebemos o entusiasmo dos alunos com nossa presença. Ao explicar a atividade e propor o consentimento de uso de som e imagem aos alunos, notamos que o entusiasmo anterior havia agora se transformado em interesse e, principalmente, curiosidade para saber como seria a atividade.

No início da aula, recolhemos os consentimentos e percebemos que a maioria dos alunos havia autorizado o que mostrou o grande interesse que tinham em participar da atividade. Em seguida, propusemos o preenchimento de um questionário prévio com o objetivo de que os alunos relatassem suas opiniões e impressões sobre vídeos.

O primeiro questionamento estava relacionado ao gosto por assistir vídeos e quais eram suas preferências. De um modo geral, percebemos que todos eles gostam e que as preferências giram em torno de temas como: clipes de músicas, tutoriais, motivacionais, vídeo-aulas, humorísticos, políticos e outros.

Quando questionados sobre a vivência de uso de vídeos pelo professor de Química, averiguamos que nenhum aluno relatou ter tido contato com este recurso durante estas aulas. Logo, nosso objetivo de desenvolver uma aula diferenciada por meio deste recurso foi alcançado.

Perguntamos se os alunos já haviam produzido algum tipo de vídeo. O Gráfico 3 representa que a maior parte dos alunos (58\%) já produziu um vídeo. Dentre estes alunos, 4 afirmaram ter feito um para um trabalho da escola no nono ano, mostrando que já tinham vivenciado a situação em outras disciplinas. O que chamou a nossa atenção foi que a maior parte das produções não tem relação com atividades escolares, mas sim com tutoriais sobre maquiagem e artesanato, game play, dança, humor, música, entre outros. Esse dado demonstra o quanto os alunos gostam de utilizar este meio para se expressar e, em nossa opinião, devem ser incentivados a fazê-lo, inclusive durante as aulas para promover a autonomia e protagonismo estudantil. 
DOI: http://dx.doi.org/10.33238/ReBECEM.2019.v.3.n.1.22069

Gráfico 3: Produção de vídeo pelos alunos

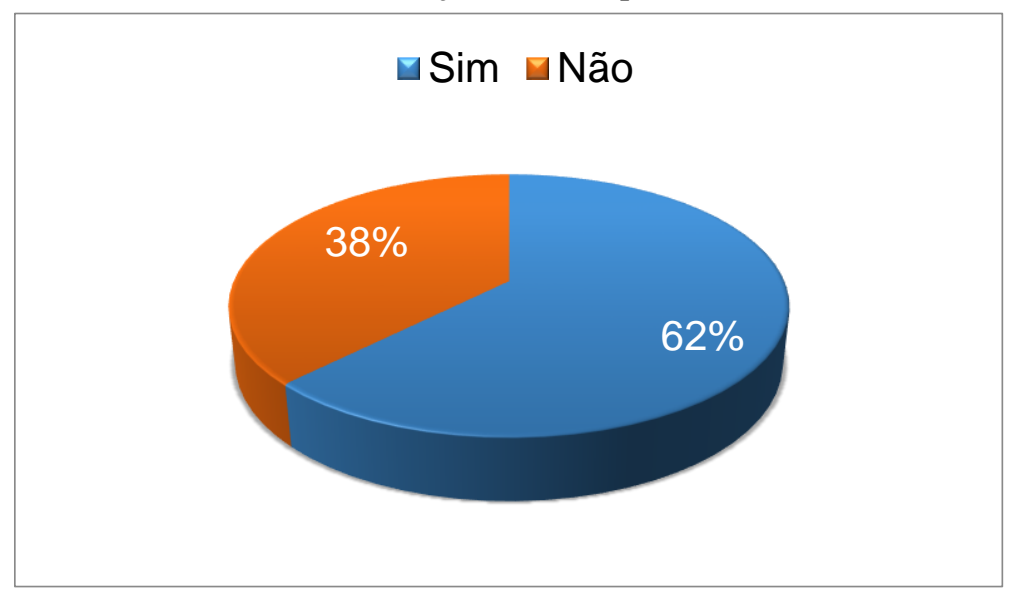

Fonte: Autoria própria (2018)

Sobre a utilização de vídeos como ferramenta pedagógica para aprender conteúdos de química, todos os alunos afirmaram que este recurso pode ser produtivo especialmente porque facilita a aprendizagem, torna a aula mais interessante e dinâmica, como pode ser observado nos relatos a seguir:

A1: Com certeza, é uma forma das pessoas entenderem com mais facilidade o conteúdo.

A2: Sim, porque os vídeos não são comuns em colégios públicos então, os alunos se interessam mais.

A3: Sim, pois ajuda o professor a dar uma aula melhor e consequentemente os alunos entendem mais coisas e a aula também fica mais dinâmica.

A4: Qualquer forma de vídeo educacional é válida.

Após a aplicação do questionário, iniciamos a aula teórica que daria embasamento para a produção da videoaula experimental. Durante a aula, notamos que a utilização do simulador foi uma ótima escolha para auxiliar as discussões, sendo que este objeto de aprendizagem chamou atenção dos alunos e os ajudou a entender os fenômenos que ocorrem durante a reação e como os fatores temperatura e concentração podem alterar a velocidade das reações.

Além do simulador, a projeção das imagens também deu suporte para a construção do conceito de "superfície de contato". Ao mencionar o conceito e explica-lo verbalmente, percebemos grande dificuldade por parte dos alunos. Porém, após a visualização das imagens, muitos conseguiram compreender do que se tratava o conceito trabalhado.

Durante a aula teórica, incentivamos a participação dos alunos com muitos questionamentos, como vínhamos fazendo em regências anteriores, para que os 
estudantes adotassem o papel de participantes ativos na construção de seu conhecimento. Assim, constatamos o crescente interesse no assunto, que ajudou no processo de aprendizagem.

Então, propusemos a produção da videoaula experimental e explicamos como seria o desenrolar da atividade. Os grupos foram montados e os temas sorteados. Cada grupo foi incentivado a escrever o roteiro de seu vídeo. Neste momento, percebemos, a partir de suas perguntas que tentavam antecipar a atividade, que realmente estavam interessados em aprender, rever os conceitos passados na aula teórica, para que seus vídeos fossem os melhores. Isto nos fez pensar na potencialidade da produção de vídeos como ferramenta de ensino, uma vez que os alunos, que eram dispersos na maior parte do tempo, estavam imersos e concentrados na atividade.

Um grupo de cinco alunos decidiu fazer o experimento com o tema "superfície de contato" focando apenas na reação química (figura 4). Ao assistir ao vídeo produzido, verificamos que este grupo optou por, primeiramente, explicar os materiais a serem utilizados no desenvolvimento do experimento. Notamos que poucos grupos comentaram as condições dos reagentes, que eram essenciais na execução do experimento. Após a apresentação do experimento, um dos alunos explicou o que foi observado e, neste momento, mostrou um pouco de dificuldade e insegurança em definir o conceito de "superfície de contato". Ele afirmou que o comprimido triturado possuía maior quantidade de partículas “quebradas". Portanto, ainda que a justificativa estivesse correta, partindo da premissa de que quanto maior a superfície de contato maior é a velocidade da reação, tivemos a sensação de que, neste momento, a justificativa foi produto da memorização, pois a explicação do conceito, feita pelo aluno, não ficou clara. Logo, o conceito acerca de superfície de contato deveria ser revisto com este grupo. 


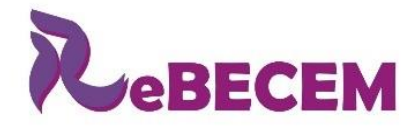

Revista Brasileira de Educação em

Ciências e Educação Matemática

ISSN 2594-9179

DOI: http://dx.doi.org/10.33238/ReBECEM.2019.v.3.n.1.22069

Figura 5: Vídeo de um dos grupos com o tema superfície de contato.

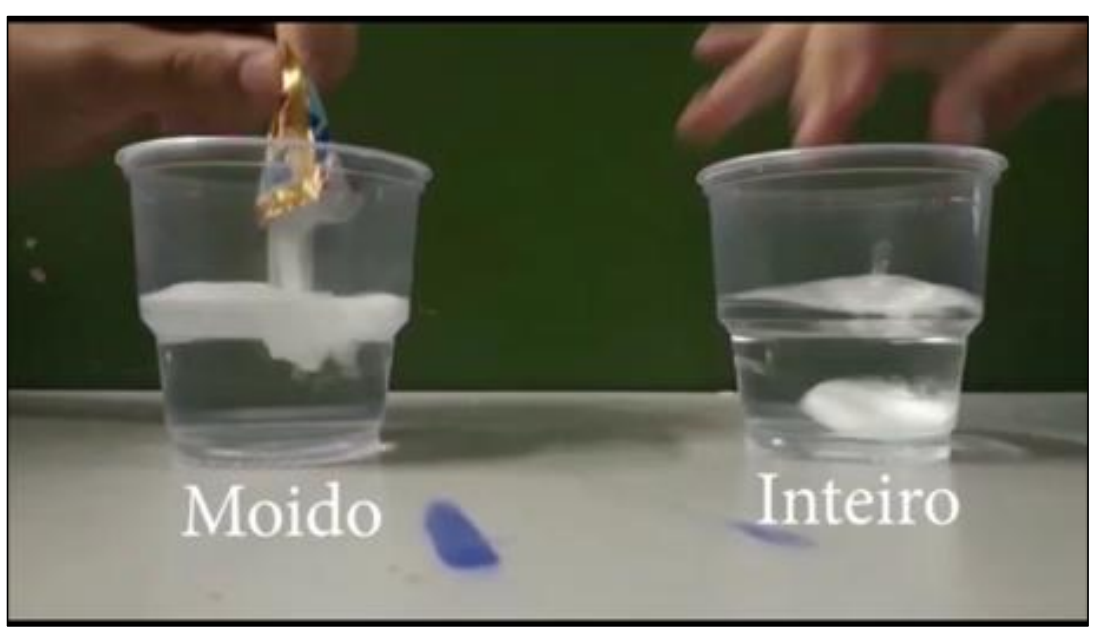

Fonte: Alunos do colégio (2018)

Ainda, ao analisar um dos vídeos produzidos, notamos que um dos grupos decidiu gravar dois representantes realizando e explicando o experimento (Figura 5). Este grupo nos surpreendeu, pois durante o momento de observação das aulas de Química percebemos que eram alunos dispersos, não demonstravam interesse pelas aulas. Porém nesta aula, além da participação, mostraram grande compreensão do conteúdo, explicando o experimento com facilidade e domínio do tema. O tema sorteado pelo grupo foi a temperatura e o aluno conseguiu explicar perfeitamente a influência da mesma na velocidade da reação química. Para isso, simplificou o termo energia cinética, para grau de agitação das moléculas, mostrando que conseguiu fazer a transposição de termos utilizados na disciplina de física para a química. Portanto, inferimos que além de causar interesse neste grupo, a produção do vídeo também os auxiliou a compreender conteúdos interdisciplinares.

Figura 6: Vídeo de um dos grupos com o tema temperatura.

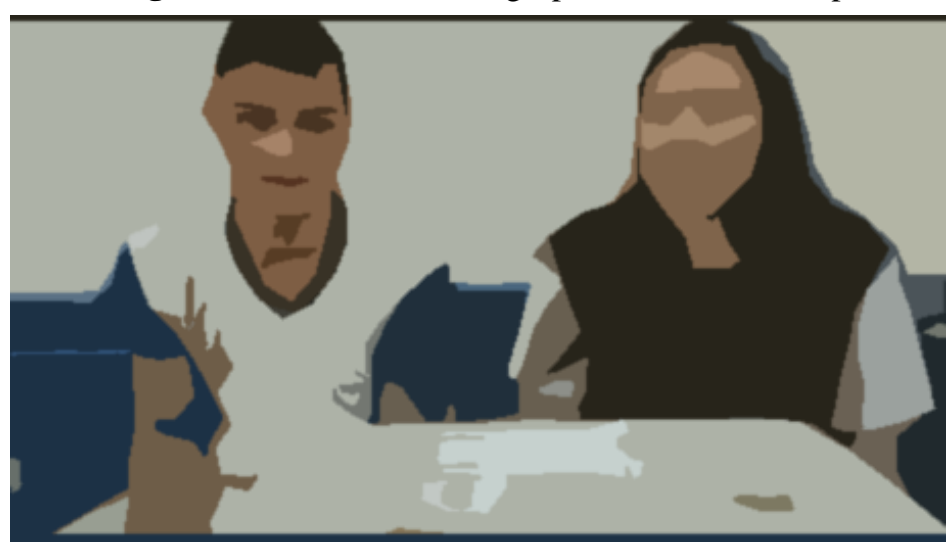

Fonte: Alunos do colégio (2018) 
Ao fim da aula, propusemos aos alunos outro questionário para conhecer e analisar suas impressões após a experiência da produção da videoaula. Este questionário também era composto por quatro perguntas. A primeira questão tinha o objetivo de colher opiniões dos alunos sobre a produção do vídeo. Nesta todos afirmam ter sido uma experiência legal e diferente. Dentre eles, ressaltamos as seguintes falas:

\section{A5: Gostei, pois ensinando, aprendemos juntos. \\ A6: Gostei, pois aprendemos e ainda podemos compartilhar.}

Estes relatos demonstram a importância do vídeo conter uma explicação a respeito do conteúdo envolvido para o processo de ensino e aprendizagem. Queremos dizer com isso que a apresentação do experimento por si só não garante a aprendizagem dos próprios envolvidos na produção e do público que possa vir a ter acesso a esse material.

Ainda, alguns alunos afirmaram que esta aula diferenciada revelou outro lado da disciplina de Química. A partir da produção dos vídeos, os alunos perceberam que a disciplina não envolve apenas a resolução de cálculos, como pode ser observado na fala:

A7: Eu amei, achei super importante e isso mostrou que a Química não é só cálculos.

Na segunda questão, perguntamos se os estudantes perceberam que aprenderam o conteúdo durante a produção do vídeo. Todos afirmam que tiveram aprendizado e ressaltaram que o "aprender fazendo" tornou esse conhecimento mais significativo, como é afirmado em:

A8: Sim, muito mais fácil aprender fazendo.

A9: Sim, porque você aprende mais na prática.

Em seguida, perguntamos aos alunos sobre a disseminação destes vídeos, em particular, se outras pessoas aprenderiam algo com eles ao assistirem o material produzido. Apenas dois alunos apresentaram dúvidas em relação a esta questão e responderam que talvez, mas que a explicação não havia sido tão efetiva, como pode ser observado nas falas:

A10: Talvez. Não foi muito bem explicado.

Após analisar o conteúdo dos vídeos, podemos dizer que todos eles tiveram uma linguagem de fácil acesso e compreensão, o que poderia sim possibilitar conhecimento a outras pessoas.

Por fim, abrimos espaço para que os alunos pudessem se manifestar com comentários e sugestões sobre a atividade, como é ilustrado por algumas falas: 
DOI: http://dx.doi.org/10.33238/ReBECEM.2019.v.3.n.1.22069

A11: Acho importante atividades diferentes.

A12: A sugestão é para ter mais atividades desse tipo, pois gostei muito da experiência.

A13: Não tenho críticas e nem sugestões, mas o conteúdo e a empolgação com isso é muita. Amei a experiência.

Em geral, eles ressaltaram a importância e o divertimento que tiveram com a experiência da produção do vídeo e pediram para que mais atividades como esta fossem aplicadas, já que as aulas são, geralmente, tradicionais. Novamente, a opinião dos alunos em relação a atividade vai de encontro com as concepções de Moran (1995), ao afirmar que o envolvimento causado pelo interesse dos estudantes pode incentivar o aprendizado.

\section{Considerações finais}

O relato vivenciado e apresentado nos possibilita concluir que a produção de vídeos tem grande potencial como ferramenta pedagógica, principalmente por instigar a curiosidade, provocar interesse e promover a participação dos alunos em sala de aula.

Também destacamos a necessidade dos docentes proporem aulas diferenciadas que envolvam diferentes objetos de aprendizagem para aproximar o conhecimento da realidade digital em que vivemos. Admitimos ser um desafio adaptar estas ferramentas a infraestrutura dos colégios, porém, não vemos isto como um obstáculo para não fazê-lo.

Concluímos as atividades propostas com um "gostinho de quero mais". Esperamos poder utilizar esta ferramenta novamente em nossa vivência docente, pois ela se mostrou muito efetiva ao facilitar o processo de ensino-aprendizagem e abrir espaço para o protagonismo e autonomia estudantil quando os alunos assumiram também o papel de professor no momento de produção das videoaulas.

\section{Referências}

BRASIL. PCN+ Ensino Médio - Ciências da Natureza. 2006. Disponível em:

<http://portal.mec.gov.br/seb/arquivos/pdf/CienciasNatureza.pdf〉. Acesso em: 22 nov. 2018.

CARNEIRO, M. L. F.; SIL VEIRA, M. S. Objetos de aprendizagem como elementos facilitadores na educação a distância. Educar em Revista, Curitiba, ed especial, n. 4, p. 235260, 2014.

CGI. Pesquisa sobre o uso das tecnologias de informação e comunicação nos domicílios brasileiros. São Paulo: Comitê Gestor da Internet no Brasil, 2017. Disponível em: <https://www.cgi.br/media/docs/publicacoes/2/tic_dom_2017_livro_eletronico.pdf>. Acesso em: 5 dez. 2018. 
CGI. Pesquisa sobre o uso das tecnologias de informação e comunicação nas escolas brasileiras. São Paulo: Comitê Gestor da Internet no Brasil, 2017. Disponível em: <https://www.cgi.br/media/docs/publicacoes/2/tic_edu_2017_livro_eletronico.pdf >. Acesso em: 22 nov. 2018.

DALE CARNEGIE DF. Velocidade das mudanças: Evolução das tecnologias de comunicação. 2009. Disponível em: 〈https://www.youtube.com/watch?v=fcDzaPuZXj8>. Acesso em: 12 dez. 2018.

GIORDAN, M. O papel da experimentação no ensino de ciências. Química Nova Na Escola, São Paulo, v. 10, p. 43 - 49, 1999.

KUENZER, A. Z. O Ensino Médio agora é para a vida. Educação \& Sociedade, Campinas, n. 70, p. 15 - 39, 2000. Disponível em: 〈http://www.scielo.br/pdf/\%0D/es/v21n70/a03v2170.pdf〉. Acesso em: 5 dez. 2018.

MORÁn, J. M. O vídeo na sala de aula. São Paulo: Comunicação e Educação, São Paulo, n. 2, p. 27 - 35, jan./abr., 1995. Disponível em:

<https://www.revistas.usp.br/comueduc/article/view/36131>. Acesso em: 5 dez. 2018.

RIBAS, A. S.; SILVA, S. DA C. R. DA; GALVÃO, J. R. Telefone celular como recurso didático no ensino de física. 1 ed. Curitiba: Ed. UTFPR, 2015.

SABANY, D. V. Olhares sobre a produção de vídeo em sala de aula. Porto Alegre: 2013. Disponível em:

<https://lume.ufrgs.br/bitstream/handle/10183/95928/000913463.pdf?sequence=1\&isAllowed= y>. Acesso em: 22 nov. 2018.

VARGAS, A.; ROCHA, H. V. DA; FREIRE, F. M. P. Promídia: Produção de vídeos digitais no contexto educacional. Novas Tecnologias na Educação, v. 5, n. 2, dez., 2007. Disponível em: <https://seer.ufrgs.br/renote/article/view/14199>. Acesso em: 5 dez. 2018.

Convidado em: 01 de março de 2019.

Submetido em: 02 de abril de 2019.

Revisado em: 30 de abril de 2019. 